\title{
Dynamic shock cushioning characteristics and vibration transmissibility of X-PLY corrugated paperboard
}

\author{
Yanfeng $\mathrm{Guo}^{\mathrm{a}, *}$, Wencai $\mathrm{Xu}^{\mathrm{b}}$, Yungang $\mathrm{Fu}^{\mathrm{a}}$ and Hongtao Wang ${ }^{\mathrm{a}}$ \\ ${ }^{a}$ Department of Packaging Engineering, Xi'an University of Technology, Xi'an, Shaanxi Prov., P.R. China \\ ${ }^{\mathrm{b}}$ Printing \& Packaging Material and Technology Beijing Area Major Laboratory, Beijing, P.R. China
}

Received 31 Augest 2008

Revised 2 July 2009

\begin{abstract}
X-PLY corrugated paperboard is a new-type corrugated paperboard with three layers of orthotropic corrugated sandwiches structure, and may be employed to protect products from shock or vibration damage during distribution. This article deals with the characterization of properties of X-PLY corrugated paperboard relevant to its application for protective packaging in distribution, such as dynamic cushioning curves, vibration transmissibility and frequency curves. The main feature of article is the evaluation on the dynamic shock cushioning characteristics and vibration transmissibility of X-PLY corrugated paperboards by a series of experimental studies on the drop shock tester and vibration tester, the establishment of experimental formulas of dynamic cushioning curves, and the analysis of peak frequencies, vibration transmissibility and damping ratios. By using the fitting polynomial of curve and method of the least mean square, the experimental formulas and characteristic coefficients of dynamic cushioning curves have been obtained. From the vibration tests with slow sine sweep, the peak frequencies and vibration transmissibility are measured and used to estimate the damping ratios. These works provide basic data and curves relevant to its application for protective packaging in distribution.
\end{abstract}

Keywords: X-PLY corrugated paperboard, dynamic shock cushioning characteristics, vibration transmissibility

\section{Introduction}

The shock and vibration experienced by goods result from the vibration of a cargo-carrying vehicle, the shock resulting from the impacts of railroad cars, and the shock caused by the handling (e.g. dropping) of packages, etc. Such goods are protected from shock and vibration damage by isolation. In general, this consists of placing the packaged item within a container, and interposing resilient means between the packaged item and the container to provide the necessary isolation. Such resilient means of protection is known as package cushioning, and may cover plastic foams, usual corrugated paperboard, etc. [1,2]. The usual corrugated paperboard is a kind of lightweight, inexpensive and environmental-friendly packaging material with corrugated sandwiches structure, and holds high strength-to-weight ratio and stiffness-to-weight ratio, favorable dynamic shock cushioning characteristics and vibration transmissibility, so it has been widely applied in transportation packaging to protect products such as precise equipment and instrument, household appliance and fragile goods etc. [3-8].

X-PLY corrugated paperboard belongs to a new-type corrugated paperboard with three layers of orthotropic corrugated sandwiches structure, which is different from usual triple-wall corrugated paperboard with three layers of parallel corrugated sandwiches structure. The ingenious construction provides it better mechanical properties [9].

\footnotetext{
*Corresponding author. E-mail: guoyf@xaut.edu.cn.
} 

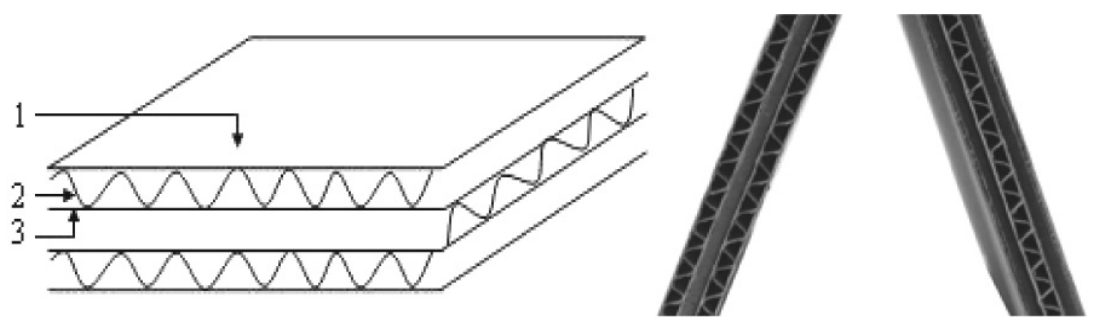

Fig. 1. Structure and photograph of the X-PLY corrugated paperboards. 1. Face sheet; 2. Corrugated core sandwich; 3. Inner sheet.

Therefore there is an increasing interest in utilizing X-PLY corrugated paperboard in protective packaging, e.g., more heavily loaded boxes, pads and pallets may be made of X-PLY corrugated paperboard. In the reference [9], the mechanical properties such as flat crush resistance, edgewise crush resistance, bursting strength and puncture resistance of X-PLY corrugated paperboard have been studied. But the lack of dynamic shock cushioning characteristics and vibration transmissibility hampers its application in transportation packaging [8,9]. So, the aims of this study are as follows: first, evaluate the dynamic shock cushioning characteristics of X-PLY corrugated paperboards by a series of drop shock tests, and establish the experimental formulas of dynamic cushioning curves. Second, investigate the vibration transmissibility of X-PLY corrugated paperboard by a series of vibration tests, and analyze the peak frequencies, vibration transmissibility and damping ratios of X-PLY corrugated paperboard at different static loads.

\section{Experimental materials and test methods}

\subsection{Experimental materials}

Experimental materials are the X-PLY corrugated paperboards, which consist of three layers of corrugated core sandwiches, two face sheets and two inner sheets (see Fig. 1). The three layers of corrugated core sandwiches are each other orthotropic along the corrugated direction. The face sheets and inner sheets have the same material, thickness and grammage. Each of corrugated core sandwiches holds same sine wave shaped corrugated flute, which forms a series of connected arches [10]. The face sheets or inner sheets are less thickness than the corrugated sandwiches.

There are two kinds of X-PLY corrugated paperboard selected as experimental materials. One is the X-PLY corrugated paperboard with three layers of A-flute (X-PLY(A) corrugated paperboard), and the other is X-PLY corrugated paperboard with three layers of B-flute (X-PLY(B) corrugated paperboard). The only difference between $\mathrm{X}-\mathrm{PLY}(\mathrm{A})$ and X-PLY(B) corrugated paperboards is the type of corrugated flute. The corrugated flute B has less height than corrugated flute A, but flute A has fewer corrugations per unit width. For X-PLY(A) and X-PLY(B) corrugated paperboards, the corrugated core sandwiches are corrugated paper with grammage of $150 \mathrm{~g} / \mathrm{m}^{2}$, and the face sheets and inner sheets are kraft linerboard paper with grammage of $175 \mathrm{~g} / \mathrm{m}^{2}$. The thicknesses of X-PLY (A) corrugated paperboard and X-PLY (B) corrugated paperboard are $14.690 \mathrm{~mm}$ and $8.778 \mathrm{~mm}$. Before each of tests, the test specimens should be preconditioned to equilibrium in air uniformly maintained for at least 24 hours at ambient temperature $23^{\circ}$ and relative humidity $60 \%$.

\subsection{Test method of dynamic shock cushioning characteristics}

The dynamic shock cushioning characteristics of package cushioning material is usually presented as a family of dynamic cushioning curves, which shows peak acceleration during impacts (drop shocks) for a range of static loads and several drop heights [1,2]. The peak acceleration is a non-dimension ratio of peak acceleration of the packaged item to gravity acceleration, which may indicate the capability of absorbing drop shock energy and express the dynamic shock cushioning characteristics. A piece of dynamic cushioning curve (or peak acceleration and static stress curve) directly reflects the relationship between peak acceleration and static stress during impacts for a range of static loads and a drop height. A family of dynamic cushioning curves may thoroughly evaluate the dynamic shock 


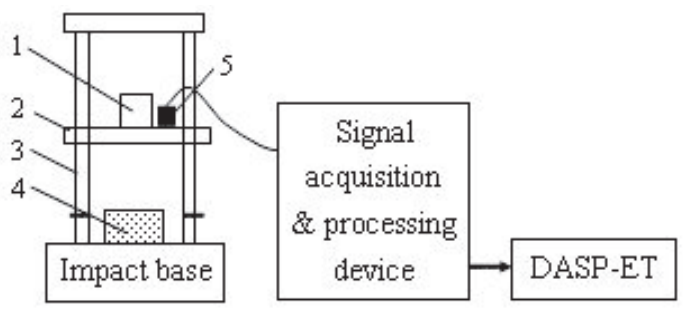

Fig. 2. Test system of dynamic shock cushioning characteristics. 1. Weight; 2. Dropping head; 3. Guide column; 4. Test specimen; 5. Acceleration sensor.

cushioning characteristics. The shape of peak acceleration and static stress curve indicates the efficiency of package cushioning material to isolate drop shock, the lower the curve swings, and the better protection the material provides. The curve has proved to be the most practical basis for describing the dynamic shock cushioning characteristics of package cushioning material $[11,12]$.

The most comprehensive method for determining dynamic shock cushioning characteristics is described in the standard ASTM D 1596 [13]. The test system (see Fig. 2) shall consist of a drop shock tester, a signal acquisition \& processing device, and a set of Data Acquisition \& Signal Processing Engineering Technology (DASP-ET) software. The mount and fixture of test specimen are shown in Fig. 2. The drop shock tester has a dropping head and weight (to represent a packaged item) and impact base for dynamic loading of a test specimen to simulate impact in handling. The weight is mounted on the dropping head. The mass of weight and drop height of the dropping head are adjustable. An acceleration sensor is mounted on the dropping head, and the signal output from the acceleration sensor is firstly fed into the signal acquisition \& processing device, then the drop shock acceleration and time curve may be read and displayed by DASP-ET. For a drop height, a piece of peak acceleration and static stress curve may be obtained by making drop shock tests for a range of static loads (or the mass of dropping head and weight). Then adjusting the drop height and making similar drop shock tests for a range of static loads, another piece of dynamic cushioning curve may be also obtained. Therefore by making a series of drop shock tests for different drop heights, a family of dynamic cushioning curves should be obtained, and the dynamic shock cushioning characteristics of X-PLY corrugated paperboard shall be evaluated on the basis of the family of dynamic cushioning curves.

The test procedure is as follows: firstly, position the test specimen on the impact base and prepare the dropping head to impact the test specimen. Secondly, impact the test specimen at the predetermined dropping head weight (static load) and drop height, then repeat the same test procedure with the other two test specimens. The drop shock acceleration and time curve should be recorded for each test. In order to eliminate the noise signals and obtain smooth drop shock acceleration and time curves, according to the sampling theorem, the sampling frequency $300 \mathrm{~Hz}$ is used for charge amplifier and filter system during the drop shock tests. The average value of peak accelerations for these three drop shock tests is taken as the peak acceleration at the predetermined static load. Thirdly, repeat the drop shock procedure with several more increments of weight until sufficient data are derived to establish the peak acceleration and static stress curve. Usually five to nine points should be required. Lastly, the same procedure shall be employed for various drop heights.

\subsection{Test method of vibration transmissibility}

The vibration transmissibility of package cushioning material is usually described as the relationship between vibration transmissibility and peak frequency at different static loads. Vibration transmissibility is a non-dimension ratio of response acceleration amplitude of the packaged item in steady-state forced vibration to excitation acceleration amplitude [1,2]. The most comprehensive method for determining vibration transmissibility is described in the standard ASTM D 4168 [14]. The test system (see Fig. 3) shall consist of a dynamoelectric vibration tester, a signal acquisition \& processing device, and a set of DASP-ET software. The mount and fixture of test specimen are shown in Fig. 3, the two test specimens combination under investigation are placed in the test fixture, and the mass block is placed on the bottom test specimen. The two test specimens, mass block and fixture (to represent a packaged item) are mounted on the vibration tester. The weight of mass block is changeable, and the static load exerted on the 


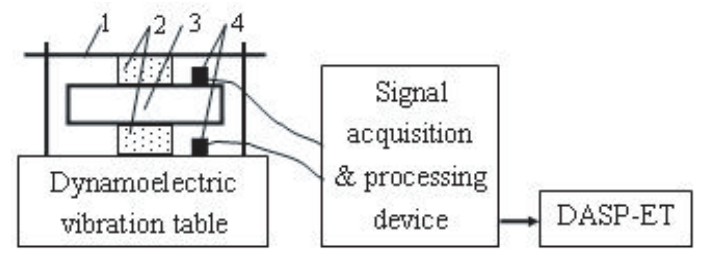

Fig. 3. Test system of vibration transmissibility. 1. Clamp device; 2. Test specimens; 3. Mass block; 4. Acceleration sensors.

bottom test specimen may be adjusted by changing the weight of mass block. One acceleration sensor is attached to the platform of vibration table to monitor the excitation acceleration, and the other is located in the mass block to measure the response acceleration. The signal outputs from the sensor located in the mass block and on the platform of vibration table are simultaneously fed into the signal acquisition \& processing device, then the experimental data shall be analyzed and presented in the form of vibration transmissibility and frequency curve by DASP-ET. So, after obtaining the vibration transmissibility and frequency curves by making a series of vibration tests with slow sine sweep for different static loads, the vibration transmissibility of X-PLY corrugated paperboard shall be evaluated.

The test procedure is as follows: firstly, place two specimens combination under investigation in the test fixture, one below and the other above the mass block. The mass block weighted for the desired static load is placed on the bottom test specimen, and the top test specimen is placed above the mass block, then the fixture is clamped in place. Secondly, start the vibration test with slow sine sweep, and present experimental data in the form of vibration transmissibility and frequency curve. In order to thoroughly evaluate the vibration transmissibility of X-PLY corrugated paperboard, the range of frequency sweep is selected from $3 \mathrm{~Hz}$ to $600 \mathrm{~Hz}$, which is much broader than plastic foams [12]. The frequency sweep rate is one octave per minute, and sine excitation acceleration is held constant amplitude at $0.5 \mathrm{~g}$ (gravity acceleration). Thirdly, the same procedure shall be used for various static loads. These static loads of bottom test specimen should be selected according the family of dynamic cushioning curves of X-PLY corrugated paperboards, eleven kinds of different static loads are selected for X-PLY(A) corrugated paperboard, and twelve kinds of different static loads are chosen for X-PLY(B) corrugated paperboard, respectively. They would be introduced in the following section of vibration transmissibility.

\section{Dynamic shock cushioning characteristics}

In this part, the dynamic shock cushioning characteristics of X-PLY corrugated paperboard is evaluated by a series of experimental studies on the drop shock tester, the characterization of dynamic cushioning curves is discussed, and the experimental formulas of dynamic cushioning curves are obtained by using the fitting polynomial of curve and method of the least mean square.

\subsection{Experimental results}

According to the test method described in the standard ASTM D 1596, the drop shock tests of X-PLY corrugated paperboards are made on the drop shock tester (see Fig. 2) for drop heights $30 \mathrm{~cm}, 60 \mathrm{~cm}$ and $90 \mathrm{~cm}$ respectively. In the procedure of drop shock tests, because majority of test specimens of X-PLY corrugated paperboard are locally crushed and the corrugated sandwiches are locally out of shape after two consecutive impacts, each of test specimens is made only for a single drop shock but not for consecutive impacts on the drop shock tester. At least nine points are selected for determining a piece of peak acceleration and static stress curve. For example, Fig. 4(a) is drop shock acceleration and time response curve of X-PLY(A) corrugated paperboard for drop height (DH) $30 \mathrm{~cm}$ and static load $2.548 \mathrm{kPa}$, Fig. 4(b) provides the curve of X-PLY(A) corrugated paperboard for drop height $60 \mathrm{~cm}$ and static load $3.038 \mathrm{kPa}$, and Fig.4(c) is the curve of X-PLY(B) corrugated paperboard while drop height $90 \mathrm{~cm}$ and static load $2.548 \mathrm{kPa}$. The waves of drop shock acceleration are similar to half-sine pulses at different static loads and drop heights. Due to the limited space, other drop shock acceleration response curves are omitted. 


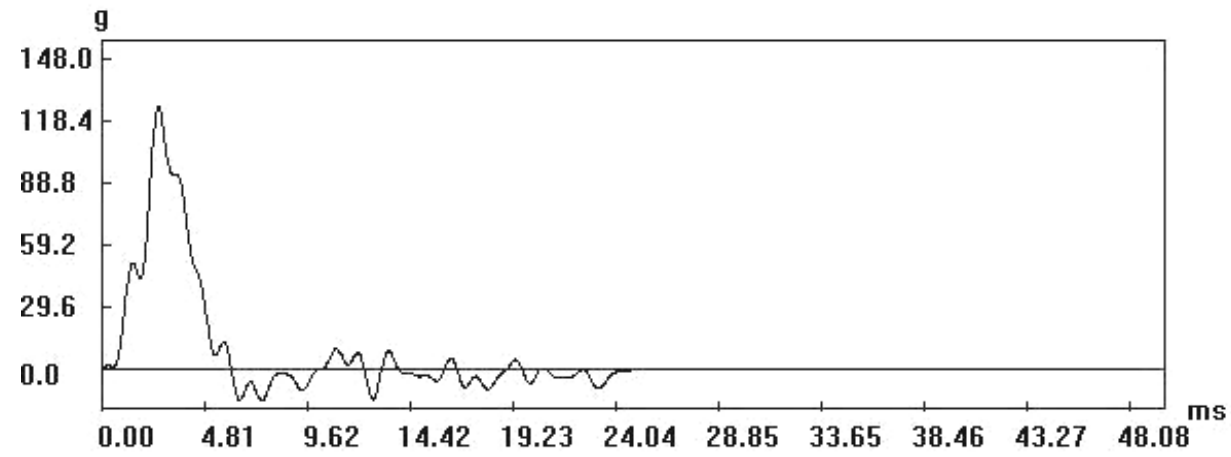

(a) X-PLY(A), $30 \mathrm{~cm}, 2.548 \mathrm{kPa}$

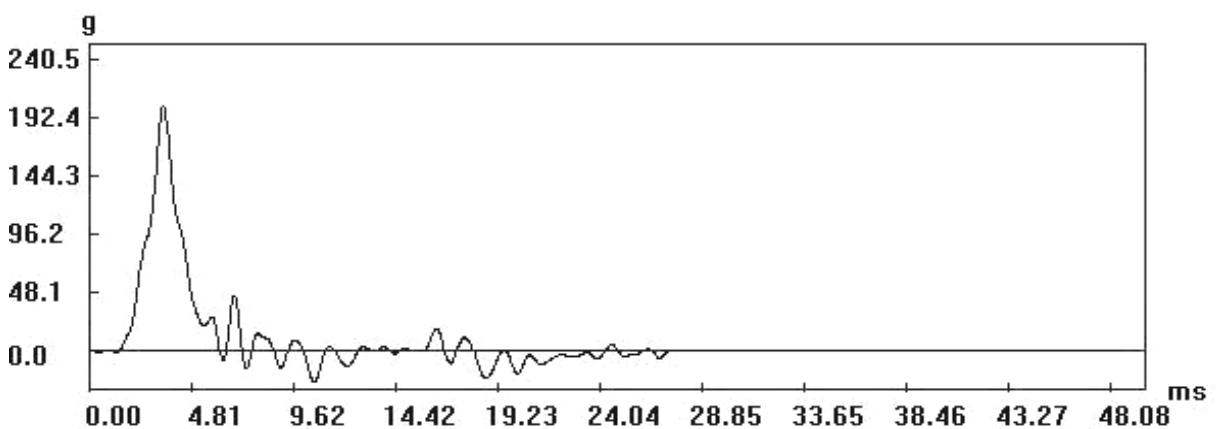

(b) X-PLY(A), $60 \mathrm{~cm}, 3.038 \mathrm{kPa}$

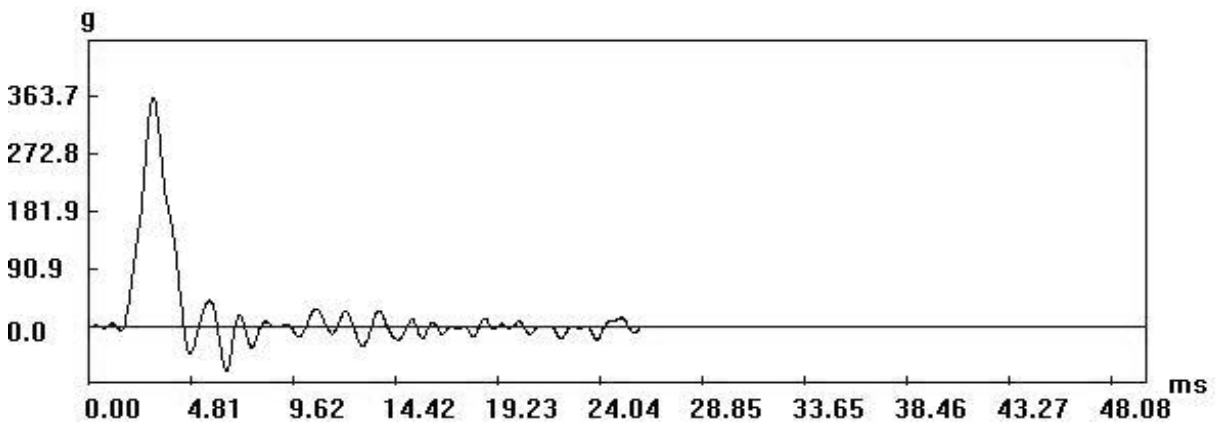

(c) X-PLY(B), $90 \mathrm{~cm}, 2.548 \mathrm{kPa}$

Fig. 4. Drop shock acceleration and time curves.

On the basis of drop shock tests of X-PLY corrugated paperboards for drop heights $30 \mathrm{~cm}, 60 \mathrm{~cm}$ and $90 \mathrm{~cm}$ for a range of static loads, six pieces of dynamic cushioning curve are obtained, which are respectively shown in Figs 5 and 6. The curves in Fig. 5 are for X-PLY(A) corrugated paperboard, yet that of Fig. 6 are for X-PLY(B) corrugated paperboard.

Because the dynamic cushioning curves are the most practical basis for utilizing them in the package cushioning design procedure, it should be necessary to obtain the experimental formulas of these curves of X-PLY corrugated paperboard [11,12]. The shapes of dynamic cushioning curves (see Figs 5 and 6) of X-PLY corrugated paperboards are always concave and upward, and each piece of the curves has only one minimum value point. These curves have a close relationship with drop height and static stress, when the drop height is constant, the peak acceleration may be described as a function of static stress, and the experimental formulas of dynamic cushioning curves may be established by using the fitting polynomial of curve [15]. By comparing and analyzing the test data of average peak acceleration and its theoretical data derived from the fitting polynomial of curve, the second order polynomial 


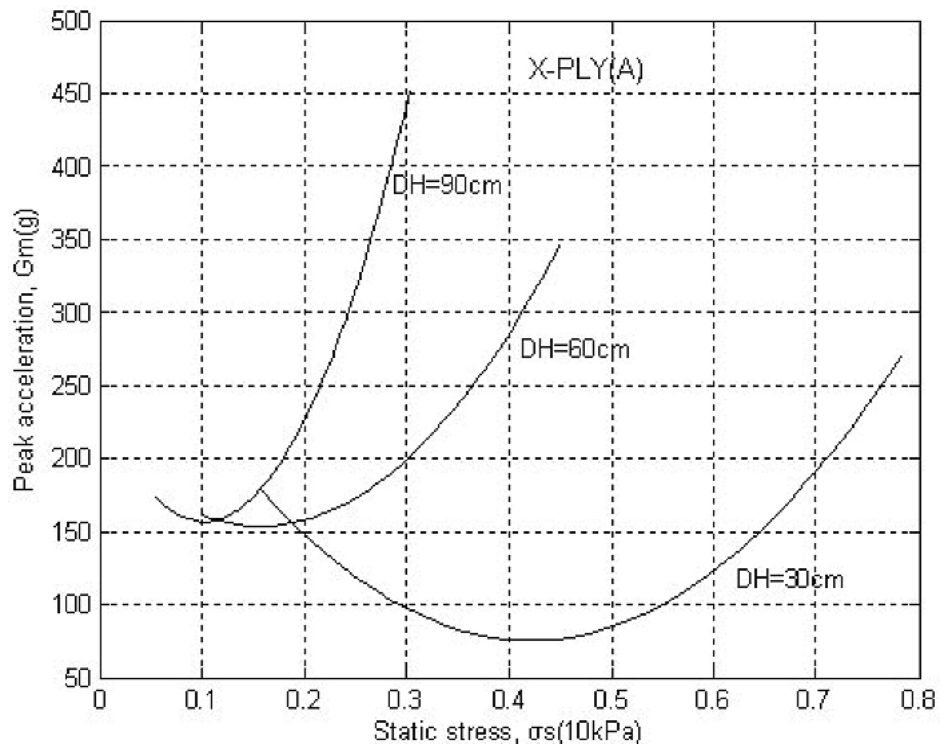

Fig. 5. Dynamic cushioning curves of X-PLY(A) corrugated paperboard.

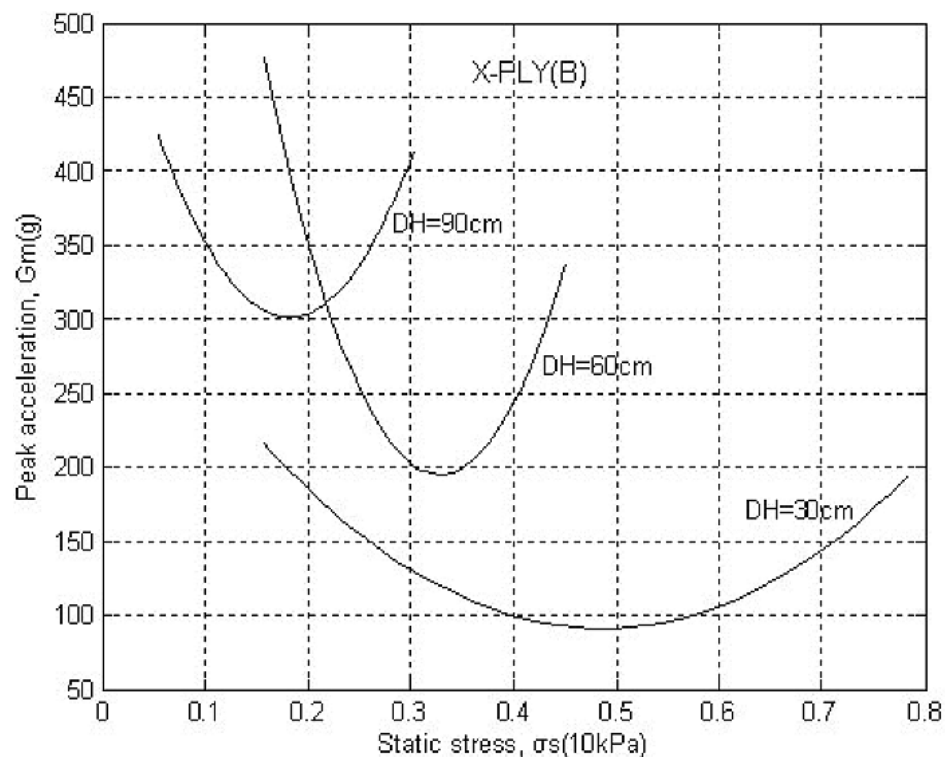

Fig. 6. Dynamic cushioning curves of X-PLY(B) corrugated paperboard.

function of static stress has proved to be the best expression. So, the experimental formulas of dynamic cushioning curves are written as the following expression

$$
G_{m}=a_{0}+a_{1} \sigma_{s}+a_{2} \sigma_{s}^{2}
$$

Where, $G_{m}$ is average peak acceleration, $\sigma_{s}$ represents static stress, $a_{0}, a_{1}$ and $a_{2}$ are three characteristic coefficients. On the basis of test data of average peak acceleration and static stress obtained from the drop shock tests of X-PLY corrugated paperboards for drop heights $30 \mathrm{~cm}, 60 \mathrm{~cm}, 90 \mathrm{~cm}$ respectively, using Eq. (1) and Method of the Least Mean Square, the characteristic coefficients of dynamic cushioning curves are solved and shown in Table 1. 
Table 1

Characteristic coefficients of dynamic cushioning curves

\begin{tabular}{ccl}
\hline Paperboard type & Drop height/cm & \multicolumn{1}{c}{$\mathrm{a}_{0}, \mathrm{a}_{1}, \mathrm{a}_{2}$} \\
\hline X-PLY(A) & 30 & $338.02,-1248.7,1482.7$ \\
& 60 & $209,-705.95,2241.4$ \\
X-PLY(B) & 90 & $232.91,-1494,7298$ \\
& 30 & $362.84,-1121.4,1154.7$ \\
& 60 & $1223.2,-6265.2,9538.2$ \\
& 90 & $550.73,-2754.9,7586.2$ \\
\hline
\end{tabular}

\subsection{Discussion}

By comparing and analyzing the dynamic cushioning curves of X-PLY corrugated paperboards (see Figs 5 and 6), some conclusions may be drawn as follows:

(1) Each piece of dynamic cushioning curves of X-PLY corrugated paperboards is always concave and upward, and has only one minimum value point. The shapes of dynamic cushioning curves of X-PLY corrugated paperboards are similar to that of plastic foams and usual corrugated paperboard, which are similar to a "smile-face" [5,12]. This can be understood if taking X-PLY corrugated paperboard as a resilient material. If the mass of weight and dropping head is very light, the drop shock would result in very little elastic deformation, X-PLY corrugated paperboard absorbs and stores a little mechanical energy per unit volume, so acceleration peak is relatively large. This represents the left hand side of dynamic cushioning curve. In the middle area, X-PLY corrugated paperboard is properly compressed and absorbs and stores much mechanical energy per unit volume, so the minimum peak acceleration shall be reached. Passing through a certain point, the greater mass of weight and dropping head compresses X-PLY corrugated paperboard too much, so X-PLY corrugated paperboard shall be bottomed out, then the minimum peak acceleration increases. This is the right hand side of the curve. So the middle area of the curve is the optimum performance range.

(2) For the same kind of X-PLY corrugated paperboard, with the increment of drop height, the concave point of dynamic cushioning curves has a trend to rise along leftward and upward direction. Therefore the drop height is an important factor to influence on the dynamic shock cushioning characteristics, and the selecting of peak acceleration and static stress curve must be coincided with the predetermined drop height in package cushioning design of X-PLY corrugated paperboard.

(3) For the same drop height, the minimum peak acceleration of X-PLY(A) corrugated paperboard is much lower than X-PLY(B) corrugated paperboard, so X-PLY(A) corrugated paperboard possess better dynamic shock cushioning characteristics than X-PLY(B) corrugated paperboard.

\section{Vibration transmissibility}

In this part, the vibration transmissibility of X-PLY corrugated paperboard at different static loads is investigated by a series of vibration tests with slow sine sweep, the characterization of vibration transmissibility and frequency curves is discussed.

\subsection{Experimental results}

According to the test method described in the standard ASTM D 4168, a series of vibration tests with slow sine sweep for X-PLY corrugated paperboards at different static loads are made on the vibration tester (see Fig. 3). In the experimental studies, the different static loads exerted on the bottom test specimen are selected according the family of dynamic cushioning curves of X-PLY corrugated paperboards. On the basis of the family of dynamic cushioning curves of X-PLY(A) corrugated paperboard (see Fig. 5), eleven kinds of different static loads $0.539 \mathrm{kPa}$, $0.980 \mathrm{kPa}, 1.568 \mathrm{kPa}, 2.058 \mathrm{kPa}, 2.548 \mathrm{kPa}, 3.038 \mathrm{kPa}, 3.528 \mathrm{kPa}, 4.018 \mathrm{kPa}, 4.998 \mathrm{kPa}, 5.978 \mathrm{kPa}, 6.958 \mathrm{kPa}$ are selected. According to the family of dynamic cushioning curves of X-PLY(B) corrugated paperboard (see Fig. 6), twelve kinds of different static loads $0.980 \mathrm{kPa}, 1.568 \mathrm{kPa}, 2.058 \mathrm{kPa}, 2.548 \mathrm{kPa}, 3.038 \mathrm{kPa}, 3.528 \mathrm{kPa}, 4.018 \mathrm{kPa}$, 


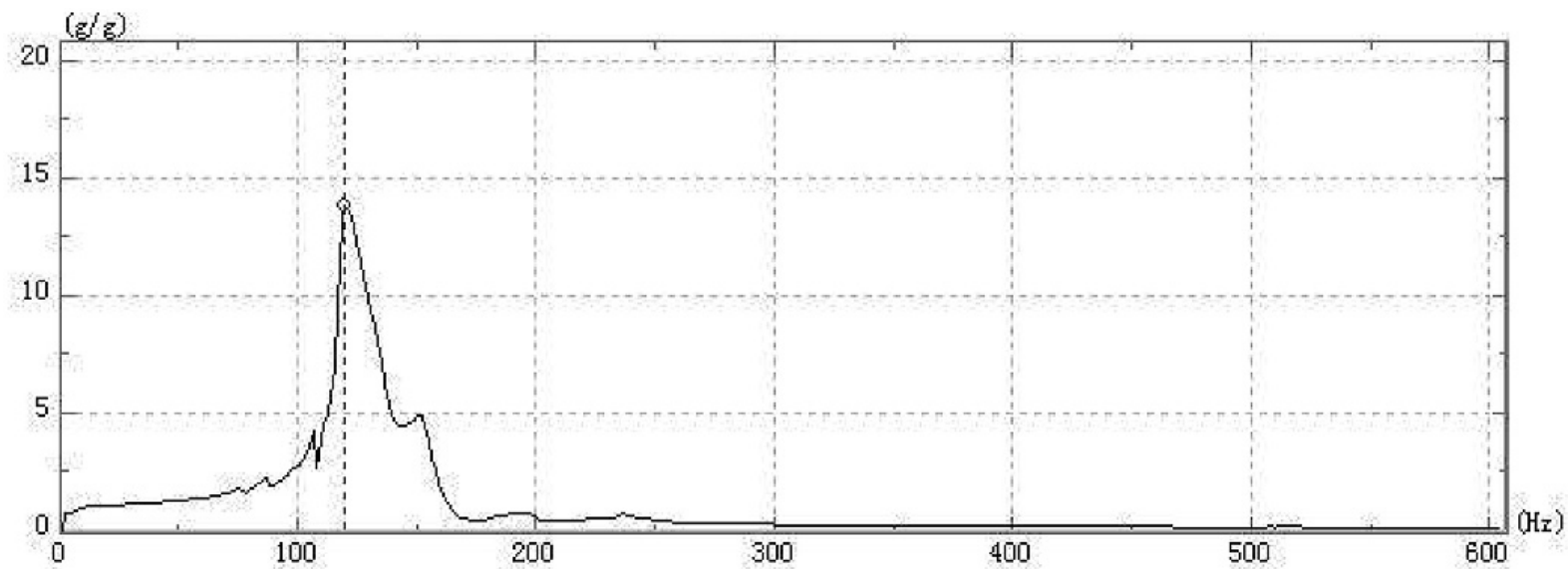

(a) X-PLY(A), $2.548 \mathrm{kPa}$

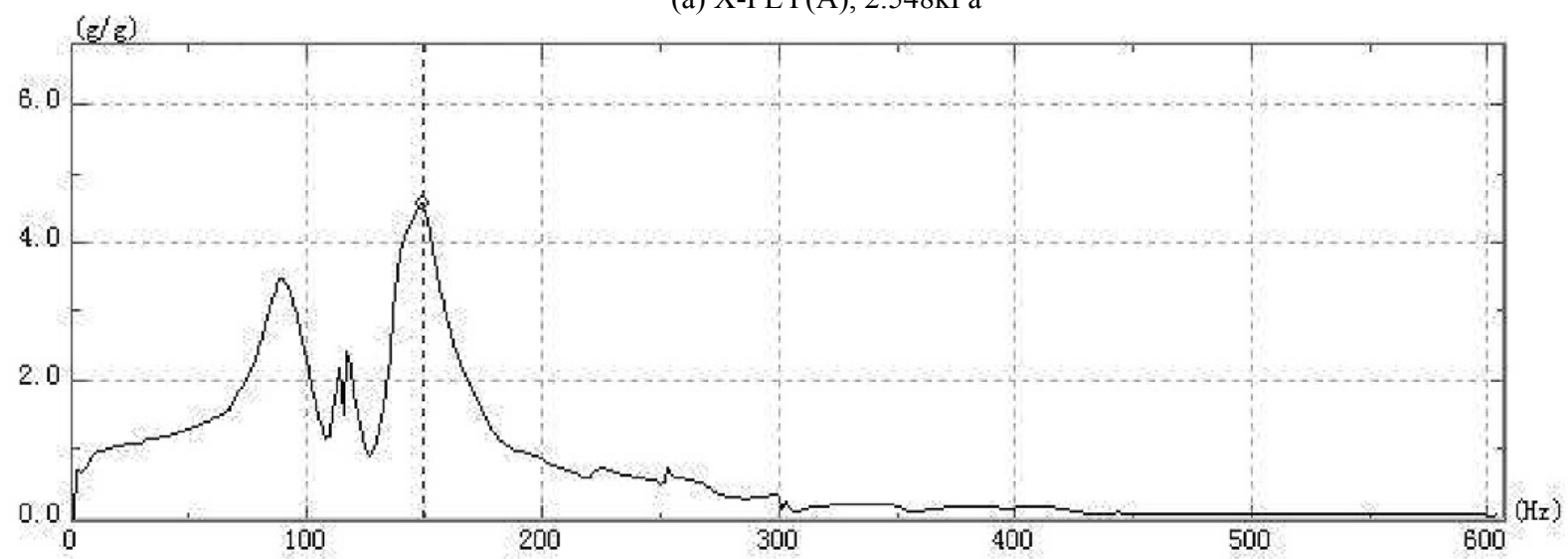

(b) X-PLY(B), $5.978 \mathrm{kPa}$

Fig. 7. Vibration transmissibility and frequency curves.

$4.508 \mathrm{kPa}, 4.998 \mathrm{kPa}, 5.978 \mathrm{kPa}, 6.468 \mathrm{kPa}, 7.448 \mathrm{kPa}$ are chosen. For example, the curve in Fig. 7(a) gives the vibration transmissibility and frequency curve of X-PLY(A) corrugated paperboard at static load $2.548 \mathrm{kPa}$, and Fig. 7(b) provides that of X-PLY(B) corrugated paperboard at static load $5.978 \mathrm{kPa}$. Due to the limited space, other vibration transmissibility and frequency curves are omitted.

On the basis of vibration transmissibility and frequency curves derived from the vibration tests with slow sine sweep, peak frequencies, vibration transmissibility and damping ratios of package cushioning system of X-PLY corrugated paperboard may be obtained, e.g., Table 2 gives the experimental results of X-PLY(A) corrugated paperboard at different static loads such as $1.568 \mathrm{kPa}, 2.548 \mathrm{kPa}, 3.038 \mathrm{kPa}, 4.998 \mathrm{kPa}, 6.958 \mathrm{kPa}$ respectively. Table 3 provides the experimental results of X-PLY(B) corrugated paperboard at different static loads such as $1.568 \mathrm{kPa}, 2.548 \mathrm{kPa}, 3.528 \mathrm{kPa}, 4.018 \mathrm{kPa}, 4.998 \mathrm{kPa}, 5.978 \mathrm{kPa}$ respectively. It should be emphasized that the damping ratios are estimated according to linear vibration theory. Due to the limited space, other experimental results are omitted.

\subsection{Discussion}

By comparing and analyzing the experimental results of vibration transmissibility and frequency curves of X-PLY corrugated paperboards at different static loads, some conclusions may be reached as follows:

(1) The package cushioning system of X-PLY corrugated paperboard has different peak frequencies, yet only several peak frequencies are primary and other peak frequencies have a little effect on packaged item during 
Table 2

Vibration transmissibility of X-PLY(A) corrugated paperboard

\begin{tabular}{|c|c|c|c|}
\hline $\begin{array}{c}\text { Static } \\
\text { load } / \mathrm{kPa}\end{array}$ & $\begin{array}{c}\text { Peak } \\
\text { frequency/Hz }\end{array}$ & $\begin{array}{c}\text { Vibration } \\
\text { transmissibility }\end{array}$ & $\begin{array}{l}\text { Damping } \\
\text { ratio }\end{array}$ \\
\hline \multirow{5}{*}{1.568} & 32 & 1.081 & \\
\hline & 94 & 1.383 & \\
\hline & 119 & 8.050 & 0.062 \\
\hline & 145 & 11.009 & 0.045 \\
\hline & 186 & 2.195 & 0.256 \\
\hline \multirow[t]{6}{*}{2.548} & 74 & 1.769 & \\
\hline & 86 & 2.211 & 0.254 \\
\hline & 106 & 4.189 & 0.123 \\
\hline & 120 & 13.917 & 0.036 \\
\hline & 152 & 4.878 & 0.105 \\
\hline & 194 & 0.666 & \\
\hline \multirow[t]{6}{*}{3.038} & 79 & 9.063 & 0.055 \\
\hline & 89 & 5.306 & 0.094 \\
\hline & 97 & 9.195 & 0.054 \\
\hline & 129 & 5.494 & 0.091 \\
\hline & 150 & 1.472 & \\
\hline & 194 & 0.134 & \\
\hline \multirow[t]{4}{*}{4.998} & 64 & 2.392 & 0.230 \\
\hline & 86 & 13.726 & 0.036 \\
\hline & 114 & 3.391 & 0.154 \\
\hline & 158 & 0.938 & \\
\hline \multirow[t]{3}{*}{6.958} & 83 & 9.657 & 0.051 \\
\hline & 138 & 1.777 & \\
\hline & 164 & 0.629 & \\
\hline
\end{tabular}

distribution. For instance, while static load $2.548 \mathrm{kPa}$ is exerted on X-PLY(A) corrugated paperboard, the vibration transmissibility and frequency curve (see Fig. 7(a) and Table 2) has six peak frequencies such as $74 \mathrm{~Hz}, 86 \mathrm{~Hz}, 106 \mathrm{~Hz}, 120 \mathrm{~Hz}, 152 \mathrm{~Hz}, 194 \mathrm{~Hz}$, their vibration transmissibility are 1.769, 2.211, 4.189, $13.917,4.878,0.666$ respectively. The vibration transmissibility at $120 \mathrm{~Hz}$ is about twenty-one times as much as that of $194 \mathrm{~Hz}$, moreover vibration transmissibility at $152 \mathrm{~Hz}$ is about seven times as much as that of $194 \mathrm{~Hz}$, so the peak frequency $120 \mathrm{~Hz}$ should be taken as the first principle mode of vibration, peak frequency $152 \mathrm{~Hz}$ as the second mode, etc. The result indicates an important guidance that the primary peak frequencies must be avoided in package cushioning design of X-PLY corrugated paperboard.

(2) In a general case, the vibration transmissibility of X-PLY(A) corrugated paperboard is very low when the peak frequency is more than $186 \mathrm{~Hz}$ (see Table 2), that of X-PLY(A) corrugated paperboard is very low when the peak frequency is more than $212 \mathrm{~Hz}$ (see Table 3), So X-PLY corrugated paperboard may efficiently attenuate vibration with higher excitation frequency during distribution.

(3) The static load has an evident influence on vibration transmissibility of X-PLY corrugated paperboard. The influence relates to the mechanical behavior of corrugated paperboard, especially viscoelasticity. The result proposes another important guidance that the vibration transmissibility and frequency curve must be selected according to the static load exerted on it in package cushioning design of X-PLY corrugated paperboard.

\section{Conclusions}

X-PLY corrugated paperboard belongs to a new-type corrugated paperboard with three layers of orthotropic corrugated sandwiches structure. The dynamic shock cushioning characteristics and vibration transmissibility of X-PLY corrugated paperboard with different flutes are evaluated by a series of experimental studies on the drop shock tester and vibration tester. The waves of drop shock acceleration are similar to half-sine pulses, the shapes 
Table 3

Vibration transmissibility of X-PLY(B) corrugated paperboard

\begin{tabular}{|c|c|c|c|}
\hline $\begin{array}{c}\text { Static } \\
\text { load } / \mathrm{kPa}\end{array}$ & $\begin{array}{c}\text { Peak } \\
\text { frequency/Hz }\end{array}$ & $\begin{array}{c}\text { Vibration } \\
\text { transmissibility }\end{array}$ & $\begin{array}{l}\text { Damping } \\
\text { ratio }\end{array}$ \\
\hline \multirow[t]{4}{*}{1.568} & 34 & 1.023 & \\
\hline & 79 & 1.408 & \\
\hline & 111 & 2.740 & 0.196 \\
\hline & 132 & 3.849 & 0.135 \\
\hline \multirow[t]{5}{*}{2.548} & 29 & 1.076 & \\
\hline & 74 & 1.417 & \\
\hline & 117 & 3.154 & 0.167 \\
\hline & 212 & 6.876 & 0.073 \\
\hline & 350 & 0.580 & \\
\hline \multirow[t]{8}{*}{3.528} & 41 & 1.112 & \\
\hline & 74 & 1.319 & \\
\hline & 85 & 1.660 & \\
\hline & 94 & 1.724 & \\
\hline & 133 & 4.896 & 0.104 \\
\hline & 156 & 2.787 & 0.192 \\
\hline & 185 & 6.279 & 0.080 \\
\hline & 336 & 0.534 & \\
\hline \multirow[t]{6}{*}{4.018} & 41 & 1.212 & \\
\hline & 79 & 3.081 & 0.172 \\
\hline & 115 & 8.107 & 0.062 \\
\hline & 152 & 3.924 & 0.132 \\
\hline & 165 & 3.676 & 0.141 \\
\hline & 361 & 0.304 & \\
\hline \multirow[t]{4}{*}{4.998} & 77 & 2.772 & 0.193 \\
\hline & 94 & 2.730 & 0.197 \\
\hline & 114 & 8.732 & 0.057 \\
\hline & 167 & 2.984 & 0.178 \\
\hline \multirow[t]{5}{*}{5.978} & 89 & 3.494 & 0.149 \\
\hline & 114 & 2.160 & 0.261 \\
\hline & 117 & 2.426 & 0.226 \\
\hline & 148 & 4.603 & 0.111 \\
\hline & 226 & 0.717 & \\
\hline
\end{tabular}

of dynamic cushioning curves are always concave and upward, and the dynamic shock cushioning characteristics of $\mathrm{X}-\mathrm{PLY}(\mathrm{A})$ corrugated paperboard is better than X-PLY(B) corrugated paperboard. The package cushioning system of X-PLY corrugated paperboard has different peak frequencies, and X-PLY corrugated paperboard may efficiently attenuate vibration with higher excitation frequency during distribution. All the works provide basic data and curves relevant to its application for protective packaging in distribution.

\section{Acknowledgements}

This work is supported by the Scientific Research Foundation of Science and Technology Department of Shaanxi Province under the Grant 2007K07-21 and the Scientific Research Foundation of Printing \& Packaging Material and Technology Beijing Area Major Laboratory under the Grant KF200705. We would like to thank Northwest Corrugated Paperboard Limited Company for providing test specimens of X-PLY corrugated paperboards.

\section{References}

[1] R.D. Mindlin, Dynamics of package cushioning, Bell System Technical Journal 24(7-10) (1945), 353-461.

[2] C.M. Harris, E.E. Crede and M.T. Hatae, Shock and Vibration Handbook, packaging design. McGraw-Hill Book Inc., New York, 1961. 
[3] E.K. Hahn, A.D. Rudo, B.S. Westerlind and L.A. Carlsson, Compressive strength of edge-loaded corrugated board panels, Experimental Mechanics 32(3) (1992), 259-265.

[4] T. Nordstrand and A. Allansson, Stability and Collapse of Corrugated Board Panels, Numerical and Experimental Analysis, Proceedings of 6th International Conference on Sandwich Structures, Florida, USA, 2003, 202-210.

[5] M. Sek and J. Kirkpatrick, Characteristics of Corrugated Fiberboard as a Cushioning Material in Protective Packaging, Proceedings of 10th IAPRI World Conference on Packaging, Melbourne, Australia, 1997, 257-266.

[6] M.E. Biancolini and C. Brutti, Numerical and experimental investigation of the strength of corrugated board packages, Packaging Technology and Science 16(2) (2003), 47-60.

[7] G.W. Kooistra, V. Deshpande and H.N.G. Wadley, Hierarchical corrugated core sandwich panel concepts, Journal of Applied Mechanics 74(1) (2007), 259-268.

[8] S. Allaoui, Z. Aboura and M.L. Benzeggagh, Phenomena governing uni-axial tensile behaviour of paperboard and corrugated cardboard, Composite Structures 87(1) (2009), 80-92.

[9] Y. Guo, W. Zhang, W. Xu and Q. Liu, Experimental Studies on Mechanical Properties of X-PLY Corrugated Paperboard with High Strength, Proceedings of 16th IAPRI World Conference on Packaging (CD edition), Bangkok, Thailand, 2008.

[10] A.C. Gilchrist, J.C. Suhling and T.J. Urbanik, Nonlinear finite element modeling of corrugated board, Mechanics of Cellulosic Materials $\mathbf{8 5}(1)$ (1999), 101-106.

[11] G.S. Mustin, Theory and Practice of Cushion Design, The Shock and Vibration Information Center, U.S. Department of Defense, 1968.

[12] U.S. Department of Defense, Military standardization handbook, package cushioning design (MIL-HDBK-304B), 1978.

[13] ASTM D 1596, Standard test method for dynamic shock cushioning characteristics of packaging materials.

[14] ASTM D 4168, Standard test method for vibration transmissibility of package cushioning material.

[15] G. Burgess, Generation of cushion curves from one shock pulse, Packaging Technology and Science 7(2) (1994), 169-173. 

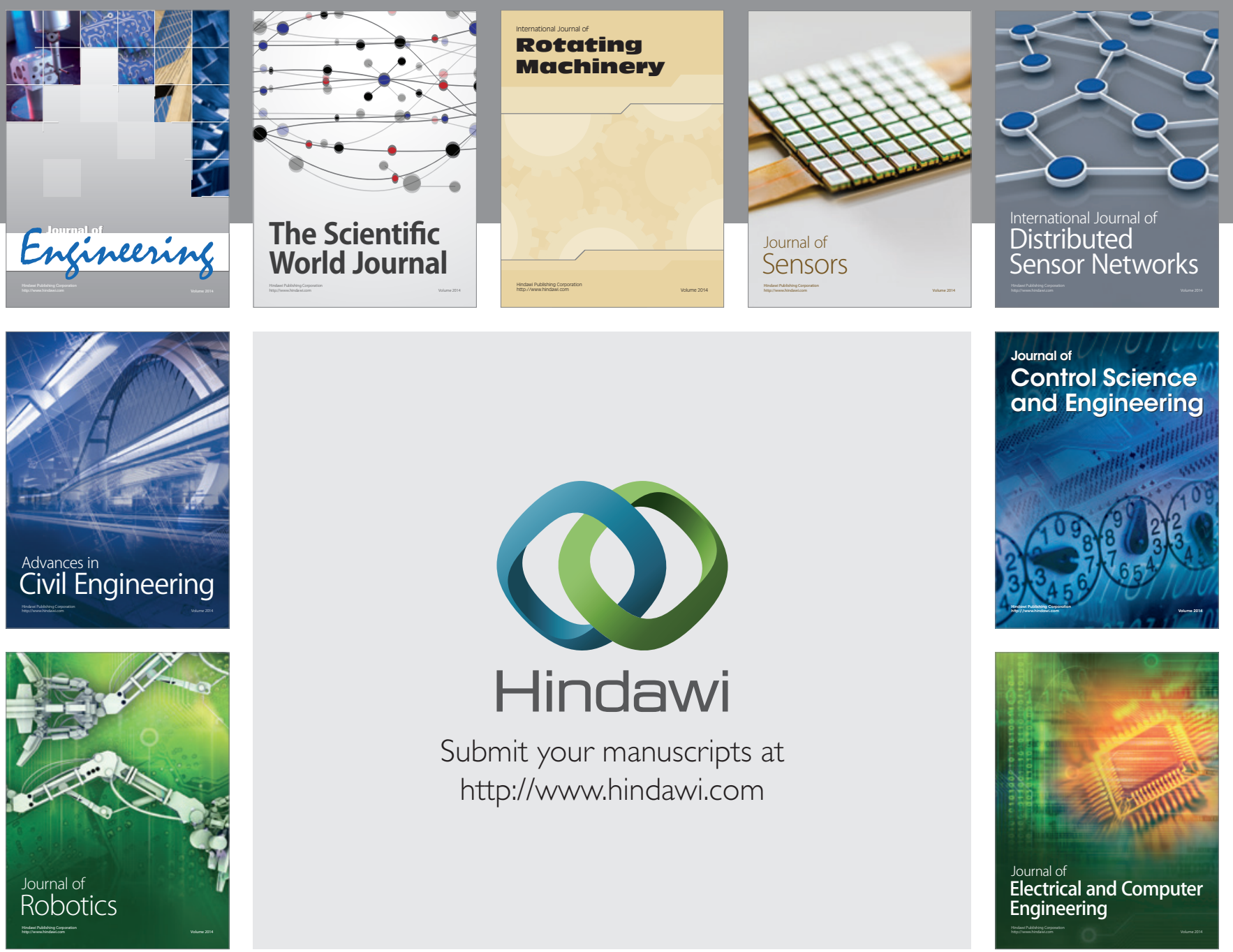

Submit your manuscripts at

http://www.hindawi.com
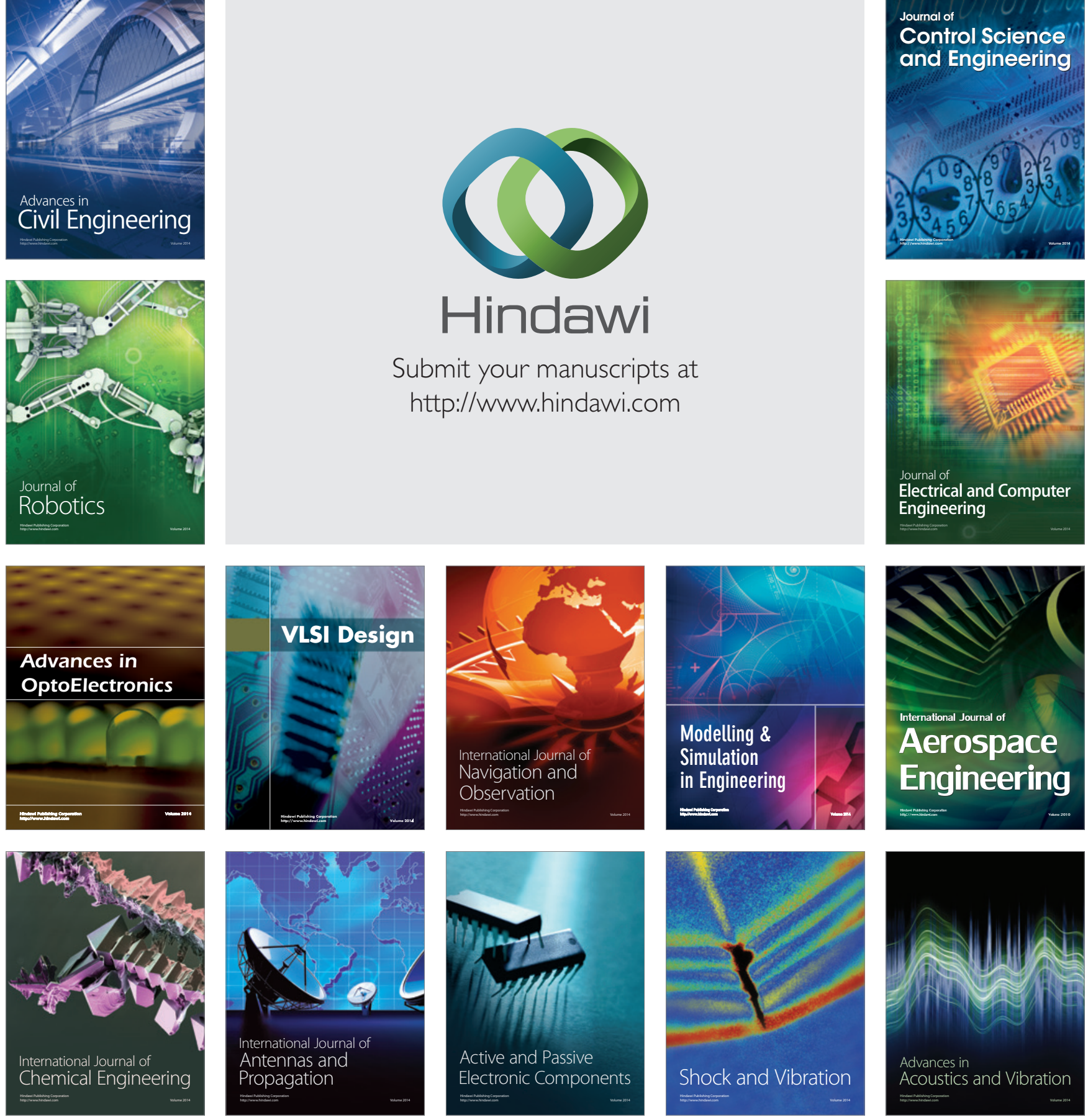